\title{
ОЦЕНКА ЭФФЕКТИВНОСТИ РАБОТЫ ИНТЕЛЛЕКТУАЛЬНОЙ СИСТЕМЫ ПОДДЕРЖКИ ПРИНЯТИЯ РЕШЕНИЙ ДЛЯ ИДЕНТИФИКАЦИИ СОСТОЯНИЯ ЛОКАЛЬНЫХ ВЫЧИСЛИТЕЛЬНЫХ СЕТЕЙ ${ }^{1}$
}

\section{EVALUATION OF THE EFFECTIVENESS OF AN INTELLIGENT DECISION SUPPORT SYSTEM FOR DETERMINING THE STATE OF LOCAL COMPUTER NETWORKS}

\section{Voronin \\ A. Gazin \\ T. Zolotareva \\ D. Skudnev \\ O. Selishchev}

Summary. This article considers the evaluation of the efficiency of an intelligent decision support system for identifying the state of local computer networks, conducted according to certain criteria: error coefficient, performance coefficient, error coefficient. The paper also considers the economic benefits of implementing the DSS.

Objective: to evaluate the efficiency of an intelligent decision support system for identifying the state of local computer networks.

Methods: efficiency assessment based on the analysis of the error coefficient, the productivity coefficient and the error coefficient, as well as the economic calculation of efficiency.

Results: an intelligent decision support system has been developed to identify the state of local computer networks, an analysis of the efficiency of its operation has been carried out.

Conclusions: the evaluation of the effectiveness of the functioning of the analyzing software module of the DSS for identifying the state of the LAN shows its importance in the work of a medium-sized company.

Keywords: intelligent decision support system; identification of the state of local computer networks; traffic analyzers.
Воронин Илья Васильевич

Старший преподаватель, ФГБОУ ВО «Липецкий государственный педагогический университет имени

П.П. Семенова-Тян-Шанского»

megaviv@yandex.ru

Газин Алексей Иванович

К.т.н., дочент, ФГБОУ ВО «Липецкий государственный педагогический университет имени

П.П. Семенова-Тян-Шанского» yearn@bk.ru

Золотарева Татьяна Александровна Старший преподаватель, ФГБОУ ВО «Липецкий государственный педагогический университет имени

П.П. Семенова-Тян-Шанского» zolotarevatatyana2016@yandex.ru Скуднев Дмитрий Михайлович К.т.н., дочент, ФГБОУ ВО «Липецкий государственный педагогический университет имени

П.П. Семенова-Тян-Шанского»

Селищев Олег Владимирович

Преподаватель, ФГБОУВО «Липецкий государственный педагогический университет имени П.П. Семенова-Тян-Шанского», г. Липецк ole9153@yandex.ru

Аннотация. В данной статье рассмотрена оценка эффективности работы интеллектуальной системы поддержки принятия решений для идентификации состояния локальных вычислительных сетей, проводившаяся по определенным критериям: коэффициент ошибок, коэффициент производительности, коэффициент ошибок. Также в работе рассмотрена экономическая выгода от внедрения СППР.

Цель: оценить эффективность работы интеллектуальной системы поддержки принятия решений для идентификации состояния локальных вычислительных сетей.

Методы: оценка эффективности на основе анализа коэффициента ошибок, коэффициента производительности и коэффициента ошибок, а также экономический расчет эффективности. 


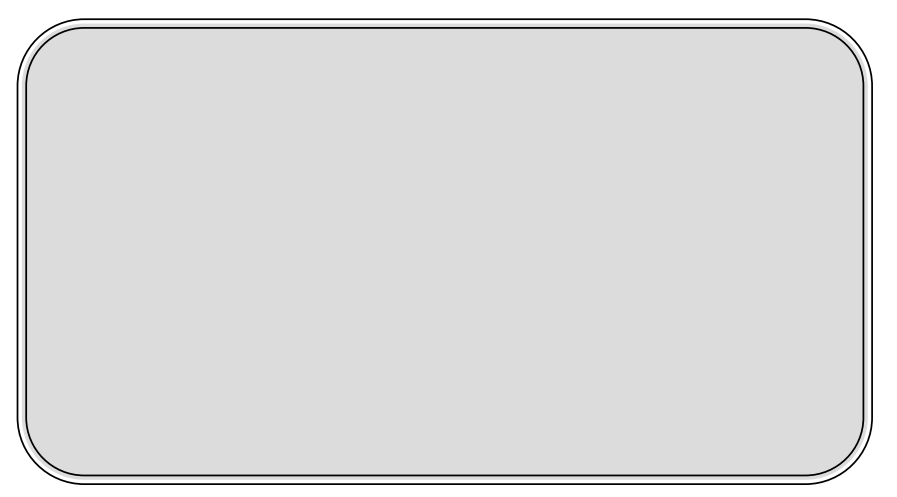

\section{Введение}

$\mathbf{P}$ еализация системы поддержки принятия решений для идентификации состояния локальных вычислительных сетей (ЛВС) представляет собой симбиоз трех главных компонент:

- статического анализатора;

- сигнатурного анализатора;

- нейросетевого анализатора.

Посредством дополнительного введения в полученный симбиоз нечетко-логических отношений следует ожидать довольно тщательной и достаточно гибкой идентификации состояния ЛВС. Рассмотрим более подробно фактическую структуру и действительную функциональность разрабатываемого программного продукта по обнаружению ошибок в ЛВС.

\section{Материалы \\ и мето $\Delta \mathrm{b}$}

Интеллектуальная система поддержки принятия решений (СППР) была разработана с применением Embarcadero Delphi. Среда разработки была выбрана для обеспечения стабильной работы программного комплекса, как на новых, так и под управлением старых операционных систем [1]. Данная программа была зарегистрирована как программа для ЭВМ (Свидетельство о государственной регистрации программы для ЭВМ «Научная обработка отчетов анализаторов сетевых трафиков» № 2021610934 от 19.01.2021 г.). Оценка реальной эффективности работы программы проводилась по определенным критериям.

Оценка подобной эффективности осуществлялась по трем главным функциональным критериям $[2,3]$ :

- коэффициент ошибок (в зависимости от типа сниффера);

- коэффициент производительности (в зависимости от объема информации);

- коэффициент ошибок (в зависимости от типа лВС).
Результаты: разработана интеллектуальная система поддержки принятия решений для идентификации состояния локальных вычислительных сетей, проведен анализ эффективности функционирования ее работы.

Выводы: оценка эффективности функционирования работы анализирующего программного модуля СППР для идентификации состояния ЛВС показывает свою значимость в работе фирмы средних размеров.

Ключевые слова: интеллектуальная система поддержки принятия решений; идентификация состояния локальных вычислительных сетей; анализаторы трафика.

Первая функциональная зависимость показывает, как отношение числа ошибочно определенных пакетов к общему числу пакетов зависит от выбора типа сниффера (тип импортируемого файла-отчета). Такая зависимость может быть представлена в виде следующей таблицы.

В графическом виде получим следующую зависимость (рис. 2).

Вторая функциональная зависимость показывает, как величина, обратная времени работы анализирующего программного модуля (АПМ), зависит от объема информации (число записей в журналах и пр.). Эта зависимость может быть представлена в виде следующей таблицы.

В графическом исполнении получим далее следующую зависимость (рис. 3).

Третья функциональная зависимость показывает, как отношение числа ошибочно определенных пакетов к общему числу пакетов зависит от выбора типа ЛВС (тип оборудования, топология и т.д.). Подобная зависимость представима в виде следующей таблицы.

В графическом виде получим следующую зависимость (рис. 4).

Очевидно, что наиболее адекватно судить об эффективности работы СППР следует по первому критерию, так как третий критерий во время экспериментов изменялся незначительно, а значимость второго существенно снижается за счет применения современных высокопроизводительных ЭВМ.

Экономическая выгода от внедрения СППР зависит от стоимости её разработки, стоимости эксплуатации и экономической прибыли, которую может обеспечить система, своевременно предупреждая нарушения работоспособности ЛВС. Представим каждый их этих показателей отдельно $[4,6]$. 
Таблица 1. Данные для 1-го коэффициента ошибок

\begin{tabular}{|l|l|}
\hline Tип сниффера & Коэффициент ошибок \\
\hline Sniffer_1 & 0,88 \\
\hline Sniffer_2 & 0,79 \\
\hline Sniffer_3 & 0,28 \\
\hline Sniffer_4 & 0,35 \\
\hline Sniffer_5 & 0,39 \\
\hline Sniffer_6 & 0,40 \\
\hline Sniffer_7 & 0,45 \\
\hline
\end{tabular}

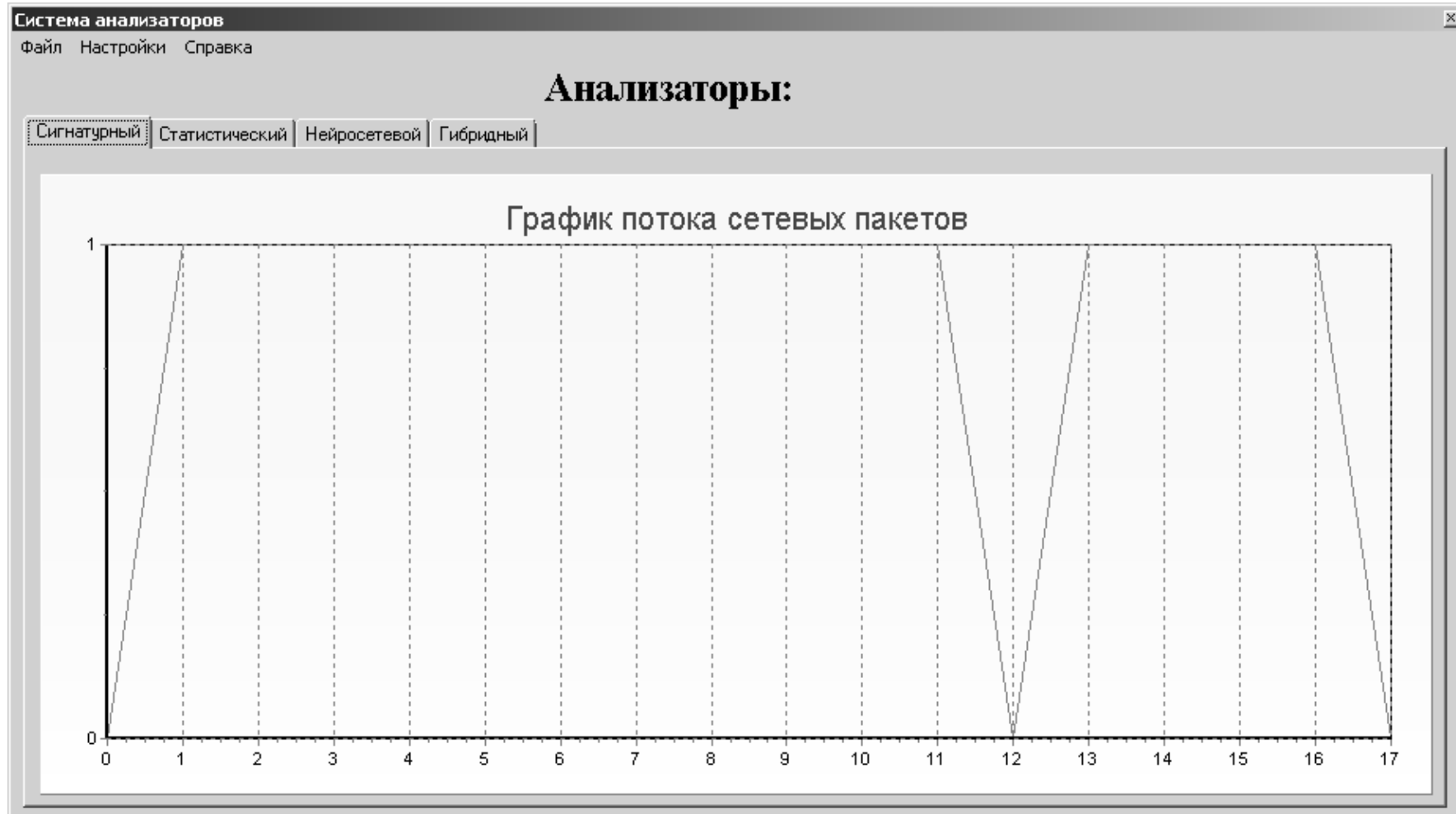

Рис. 1. Главное окно программы для ЭВМ «Научная обработка отчетов анализаторов сетевых трафиков»

Стоимость разработки СППР. Экспериментальные данные, необходимые для расчета:

- число экспертов - 2;

- оплата консультаций экспертов - 1500 руб./час;

- примерное время работы экспертов - 40 ч.

- число программистов - 2;

- заработная плата программистов - 1500 руб./ час;

- примерное время работы программистов - 140 4.

Вычислим стоимость разработки программного обеспечения посредством следующей формулы:
$S=2 * 1500 * 140+2 * 2500 * 40=540000$ руб.

Стоимость эксплуатации СППР. Экспериментальные данные для расчета стоимости эксплуатации системы:

- число обслуживающего персонала - 1 человек;

- заработанная плата обслуживающего персонала в месяц - 35000 руб;

- затраты на электроэнергию в месяц - 900 руб.;

- затраты на обработку служебной информации в месяц - 2000 руб.

Значит, исходя из формулы расчета эксплуатации СППР, получаем: 
Таблица 2. Данные для коэффициента производительности

\begin{tabular}{|l|l|}
\hline Число записей & Коэффициент производительности, мс ${ }^{-1}$ \\
\hline 100 & 0,5 \\
\hline 200 & 0,4 \\
\hline 300 & 0,38 \\
\hline 400 & 0,31 \\
\hline 500 & 0,27 \\
\hline 1000 & 0,12 \\
\hline 2000 & 0,08 \\
\hline
\end{tabular}

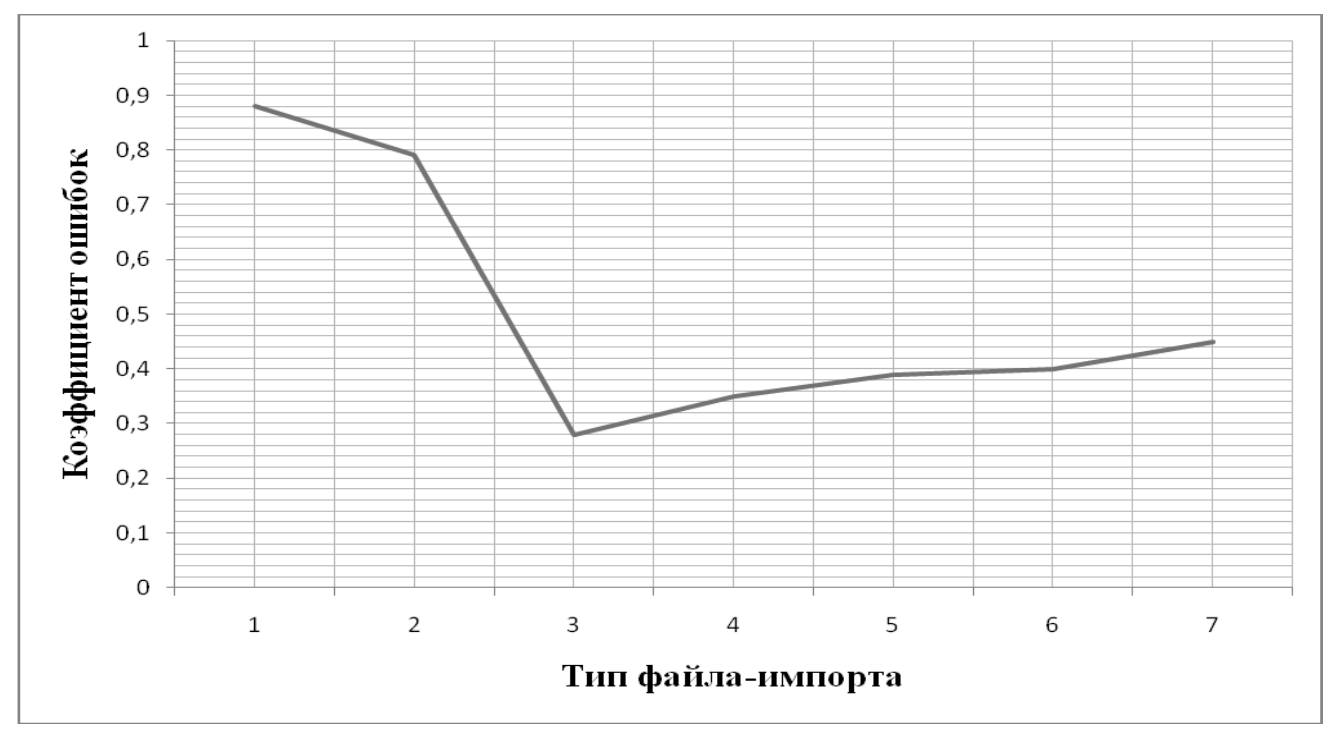

Рис. 2. График зависимости коэффициента ошибок от типа сниффера

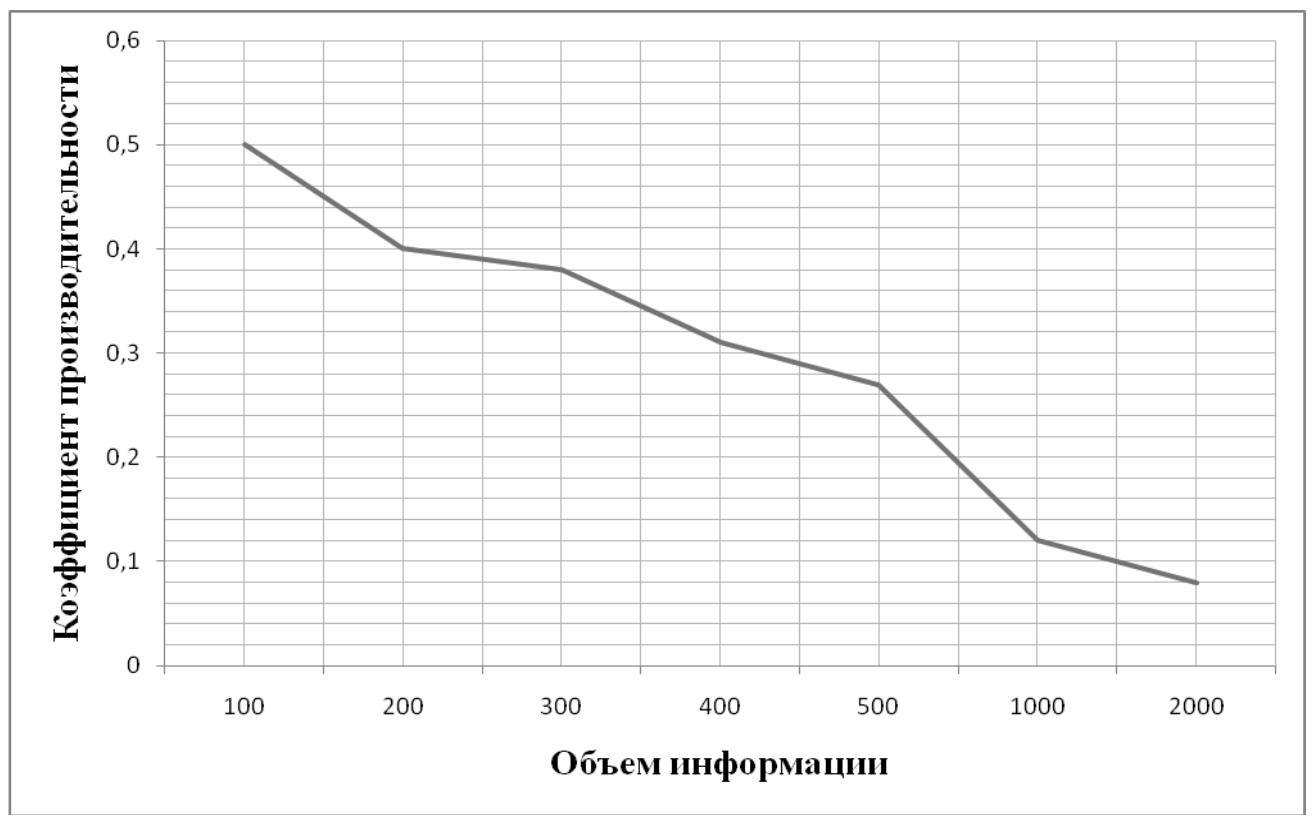

Рис. 3. График зависимости коэффициента производительности от объема информации 
Таблица 3. Данные для 2-го коэффициента ошибок

\begin{tabular}{|l|l|}
\hline Tип сниффера & Коэффициент ошибок \\
\hline LAN_1 & 0,89 \\
\hline LAN_2 & 0,88 \\
\hline LAN_3 & 0,78 \\
\hline LAN_4 & 0,75 \\
\hline LAN_5 & 0,79 \\
\hline LAN_6 & 0,80 \\
\hline LAN_7 & 0,85 \\
\hline
\end{tabular}

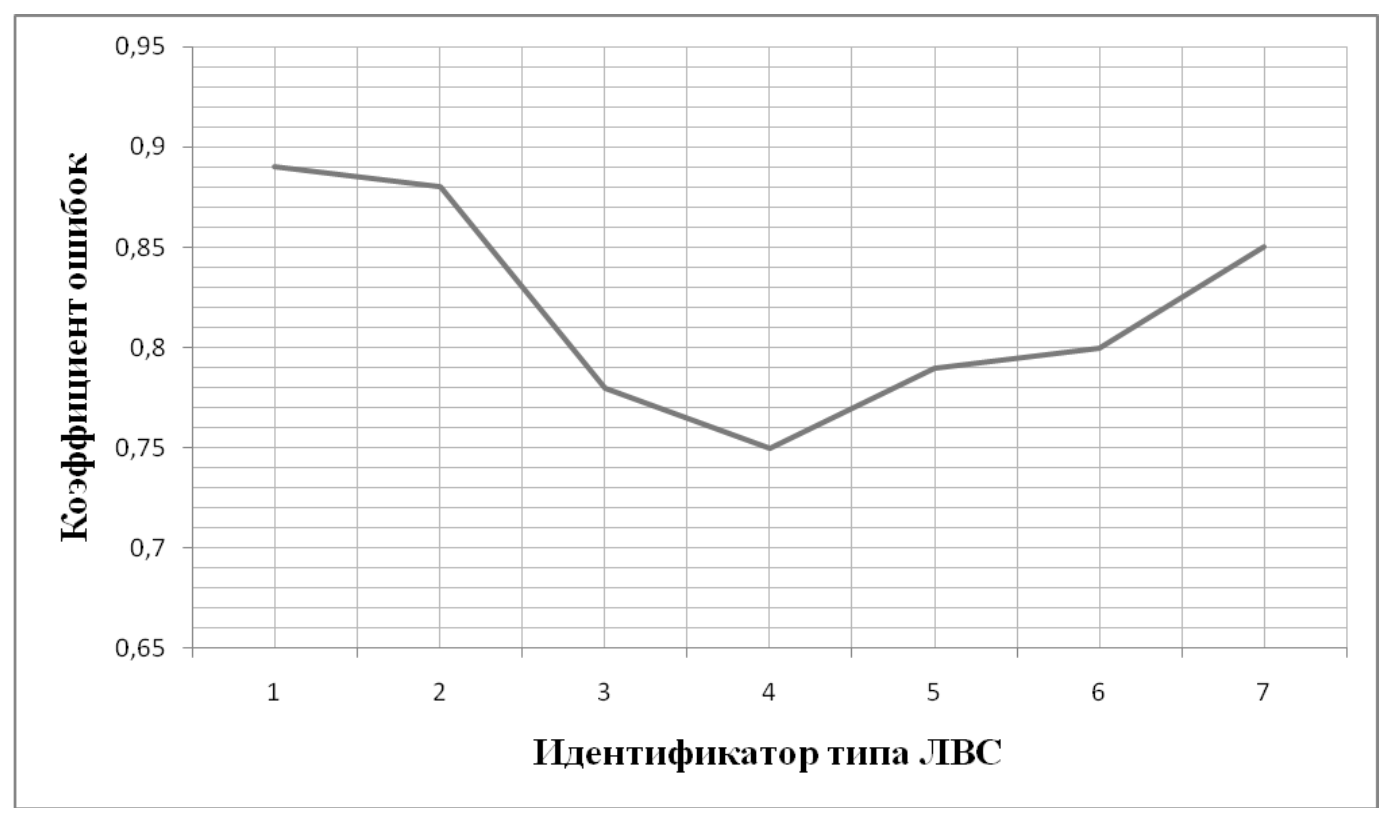

Рис. 4. График зависимости коэффициента ошибок от типа ЛВС

$Z u=37900$ руб./месяц или 454800 руб./год.

Очевидно, итоговые затраты на разработку и эксплуатацию интеллектуальной СППР составят примерно 994800 руб. в первый год. За каждый последующий год эксплуатации придется затратить 454800 руб.

Экономическая выгода от внедрения СППР. Рассчитаем экономическую выгоду от внедрения системы на примере предотвращения выхода из строя одного сегмента ЛВС. Расчёты проведем для самого критического случая, когда выход из строя узла ЛВС приводит к очень длительному простою узла из-за значительного времени на обнаружение, идентификацию неисправности и последующее восстановление. Экспериментальные данные для расчета:

- время простоя узла вследствие возникновения проблем - 2 ч;

- время восстановления узла после проблем - 54;

- число обслуживающего персонала - 1;
- зарплата обслуживающего персонала 35000 руб./месяц;

- число потенциально сбойных узлов или сегментов ЛВС -1 ;

- число выходов из строя вследствие проблем - 1;

- число остановок узла в год - не более 10.

Пусть отсутствуют потери от уменьшения производительности сотрудников сбойного узла ЛВС. Оборудование узла при его восстановлении не модифицировалось.

Пусть максимальный доход, получаемый руководством от постоянной работы в течении года узла ЛВС, по средним текущим расценкам составляет $O \approx 20$ млн. руб.

Следовательно, максимальная упущенная выгода по причине сбоя одного узла ЛВС может составить: 


$$
U \approx \frac{20000000}{40 \cdot 7 \cdot 8}(2+5) \cdot 10=625000 \text { руб. }
$$

Представленные возможные риски подтверждают справедливость внедрения интеллектуальной СППР для идентификации состояния всех элементов ЛВС средней фирмы.

Следует подчеркнуть, что представленная методика расчета экономической эффективности внедрения интеллектуальной СППР не учитывает ряда факторов, влияющих на риск нанесения ущерба предприятию. К таким факторам относятся $[3,5]$ :

- стабильность оборудования и программного обеспечения;

- текучесть кадров (приводит к увеличению затрат на обучение сотрудников);

- устойчивость структуры ЛВС в результате возникновения различных сетевых проблем и др.
Выход из строя отдельных узлов ЛВС наносит также косвенные потери фирме в виде:

- невозможности выполнения договорных обязательств;

- ущерба деловой репутации;

- приостановление деятельности в связи блокировкой данных и др.

\section{Зак^ючение}

Таким образом, оценка эффективности функционирования работы анализирующего программного модуля СППР для идентификации состояния ЛВС показывает свою значимость в работе фирмы средних размеров. Были предложены как программно-технические критерии, так и экономические критерии для наиболее развернутого исследования особенностей АПМ СППР. Также были выявлены приоритеты в практическом применении подобного программного комплекса.

\section{ЛИТЕРАТУРА}

1. Бакнелл, Дж. Фундаментальные алгоритмы и структуры данных в Delphi — Текст: непосредственный / Дж. Бакнелл. — СПб.: Изд-во Питер, 2006. 560 стр.

2. Семенцов Н.С. Методика оценки программного и информационного обеспечения - Текст: непосредственный // Имущественные отношения в Российской Федерации. - 2020. - № 3(222). - С. 43-58.

3. Воронин, И.В. Роль систем поддержки принятия решений в управленческой деятельности организации / И.В. Воронин, А.И. Газин, В.С. Зияутдинов, Т.А. Золотарева, 0.В. Селищев, Д.М. Скуднев — Текст: непосредственный // Актуальные вопросы современной науки. — 2019. — № 4 (24). — С. 23-27.

4. Мальков А. Оценка экономической эффективности внедрения автоматизированной системы [Электронный ресурс] / NTR Lab — M., 2003 — Peжим доступа: http://www.ntrlab.ru

5. Руденко, А.С. Внедрение на предприятии системы поддержки принятия решений / А.С. Руденко, А.С. Кравченко, Д.В. Гудков. - Текст: непосредственный // Молодой ученый. - 2020. — № 25 (315). - С. 125-128.

6. Обоснование экономической эффективности внедрения системы поддержки принятия решения [Электронный ресурс].— Режим доступа: httрs:// studbooks.net/2164012/informatika/obosnovanie_ekonomicheskoy_effektivnosti_vnedreniya_sistemy_podderzhki_prinyatiya_resheniya_podboru_ tovarov.

( ) Воронин Илья Васильевич ( megaviv@yandex.ru ), Газин Алексей Иванович ( yearn@bk.ru),

Золотарева Татьяна Александровна (zolotarevatatyana2016@yandex.ru ), Скуднев Дмитрий Михайлович,

Селищев Олег Владимирович (ole9153@уandex.ru).

Журнал «Современная наука: актуальные проблемы теории и практики» 